\title{
SISTEM MONITORING NILAI SISWA BERBASIS ANDROID
}

\author{
Salamun \\ Jurusan Teknik Informatika, Fakult Teknik, Universitas Abdurrab \\ J1. Riau Ujung no.73 Pekanbaru \\ E-Mail :Salamun@univrab.ac.id
}

\begin{abstract}
ABSTRAK
Perangkat bergerak pada saat ini sudah merajai dunia teknologi dalam berbagai bidang, dalam penggunaannya perangkat bergerak atau mobile phone memiliki bermacam-macam operasi sistem yaitu, Andorid, IOS, Symbian dan beberapa operasi sistem lainnya, dengan memanfaatkan mobile phone sebagai wadah untuk mengembangkan ilmu pengetahuan di bidang teknologi sangat membantu para pengembang ilmu pengetahuan untuk mengembangkan berbagai pemikiran mereka. Dalam penelitian ini penulis melakukan sebuah inovasi di dunia pendidikan dengan memanfaatkan mobile phone dengan sistem operasi android. Metode yang di lakukan adalah melakukan anilsa kebutuhan dunia pendidikan pada saat ini, maka dari itu hasil dari penelitian ini adalah bagaiman sebuah mobile phone dengan sistem operasi android dapat mengolah data nilai siswa, memberikan informasi seputar kemajuan siswa di sekolah. Aplikasi pengolahan nilai berbasis android ini nantinya dapat menampilkan daftar nilai siswa, kegiatan siswa, serta kehadiran siswa di sekolah. Maka para orang tua cukup mengunduh aplikasi ini dan memasang di handphone mereka agar dapat memantau perkembangan anak mereka di sekolah.
\end{abstract}

Kata Kunci : perangkat bergerak,Android, sistem operasi

\section{ABSTRACT}

Today's mobile devices have dominated the world of technology in various fields, in the use of mobile devices or mobile phones have a variety of operating systems namely, Andorid, IOS, Symbian and some other system operations, by using mobile phone as a container to develop science in the field of technology is very helpful to the developers of science to develop their various thoughts. In this study the authors make an innovation in the world of education by utilizing mobile phone with android operating system. The method is doing anilsa needs of the education world at this time, therefore the result of this research is how a mobile phone with android operating system can process student value data, provide information about the progress of students in school. This android based value processing app will be able to display a list of student values, student activities, and student attendance at school. So the parents simply download this application and install on their mobile phone in order to monitor the development of their children in school.

Keywords: mobile device, Android, operating system

\section{PENDAHULUAN}

Membangun pola komunikasi antara institusi pendidikan dan orang tua siswa memang menjadi salah satu upaya untuk mencapai kemajuan pendidikan Indonesia yang lebih baik. Jika keduanya belah pihak saling bekerja sama, maka akan tumbuh generasi penerus yang taat peraturan dan lebih berwawasan.

Namun selama ini pengawasan terhadap siswa sebagian besar hanya dilakukan oleh pihak sekolah. Dengan tingkat kesibukan yang tinggi, orang tua minim melakukan memonitor terhadap perkembangan anakanaknya di sekolah. Informasi tentang perkembangan proses belajar siswa biasanya hanya diterima orang tua sekali dalam satu semester, yakni saat terima raport. Jika siswa melakukan pelanggaran, maka pihak sekolah akan memanggil orang tua dengan cara

mengirimkan surat panggilan. Biasanya pelangaran yang dilakukan meliputi absensi, nilai, keterlambatan pembayaran uang sekolah (uang OSIS), dan kasus-kasus pelanggaran lain yang dilakukan siswa. Hal ini tentu tidak memberikan banyak solusi karena orang tua tidak memberikan pengawasan sejak awal. Kondisi pengawasan seperti ini terjadi di SMAN 1 Bandar Sekijang yang berada di Kecamatan Bandar Sekijang, 
Kabupaten Pelalawan. Pengawasan dan kontrol yang dilakukan terhadap siswa tidak sesuai dengan kemajuan teknologi yang berkembang saat ini.

Berdasarkan pemaparan di atas, penulis tertarik untuk membuat sebuah sistem yang dapat mempermudah orang tua dan guru dalam melakukan pengawasan terhadap siswa. Orang tua bisa melakukan proses monitoring proses belajar anak-anaknya dengan perangkat Android mereka. Sistem ini bisa diakses dengan melakukan login dengan Nomor Induk Siswa. Setelah login, orang tua bisa melihat nilai, absensi, pembayaran uang sekolah, prestasi atau kasus-kasus yang dilakukan oleh anaknya di sekolah. Pihak sekolah bisa memberikan laporan yang akurat, dan orang tua murid bisa mendapat informasi perkembangan anak secara real time.

\section{Sistem}

Sistem adalah suatu jaringan kerja dari prosedur-prosedur yang saling berhubungan, berkumpul bersama-sama untuk melakukan suatu kegiatan atau untuk menyelesaikan suatu sasaran yang tertentu. Suatu sistem memiliki karakteristik atau sifat-sifat tertentu, yaitu : komponen sistem, batas sistem, lingkungan luar sistem, penghubung sistem, masukan sistem, keluaran sistem, pengolah sistem, dan sasaran sistem (Jogiyanto, 2009:1)

\section{Sistem Monitoring}

Sistem monitoring merupakan sistem yang didesain untuk bisa memberikan feedback ketika program sedang menjalankan fungsinya. Feedback dimaksudkan untuk memberikan informasi keadaaan sistem pada saat itu. Sistem monitoring juga dapat diartikan sebagai kumpulan prosedur dan program untuk mengkomputasi sistem informasi yang didesain untuk mencatat dan mentransmisikan data berdasarkan informasi yang diperoleh. Selain itu sistem monitoring adalah kumpulan fitur informatif yang memberikan informasi mengenai apa saja yang terjadi dengan sistem yang di-monitor.

\section{Aplikasi Mobile}

Menurut Buyens (2001) aplikasi mobile berasal dari kata application dan mobile. Application yang artinya penerapan, lamaran, penggunaan. Secara istilah aplikasi adalah program siap pakai yang direka untuk melaksanakan suatu fungsi bagi pengguna atau aplikasi yang lain dan dapat digunakan oleh sasaran yang dituju sedangkan mobile dapat di artikan sebagai perpindahan dari suatu tempat ke tempat yang lain.

Kata mobile mempunyai arti bergerak atau berpindah, sehingga aplikasi mobile menurut Purnama (2010) adalah sebutan untuk aplikasi yang berjalan di mobile device. Dengan menggunakan aplikasi mobile, dapat dengan mudah melakukan berbagaii macam aktifitas mulai dari hiburan, berjualan, belajar, mengerjakan pekerjaan kantor, browsing dan lain sebagainya.

Pemanfaatan aplikasi mobile untuk hiburan paling banyak digemai oleh pengguna telepon seluler, karena dengan memanfaatkan adanya fitur game, music player, sampai video player membuat kita mejadi semakin mudah menikmati hiburan kapan saja dan dimanapun.

Perangkat mobile memiliki banyak jenis dalam hal ukuran, desain dan layout, tetapi mereka memiliki kesamaan karakteristik yang sangat berbeda dari sistem desktop, yaitu antara lain :

1. Ukuran yang Kecil

Perangkat mobile memiliki ukuran yang kecil. Konsumen menginginkan perangkat yang terkecil untuk kenyamanan dan mobilitas mereka. 
2. Memori yang Terbatas

Perangkat mobile juga memiliki memory yang kecil, yaitu primary (RAM) dan secondary (disk). Pembatasan ini adalah salah satu faktor yang mempengaruhi penulisan program untuk berbagai jenis dari perangkat ini. Dengan pembatasan jumlah dari memory, pertimbangan-pertimbangan

khusus harus diambil untuk memelihara pemakaian dari sumber daya yang mahal ini.

3. Daya Proses yang Terbatas

Sistem mobile tidaklah setangguh rekan mereka yaitu desktop. Ukuran, teknologi dan biaya adalah beberapa faktor yang mempengaruhi status dari sumber daya ini. Seperti hard disk dan RAM, Anda dapat menemukan mereka dalam ukuran yang pas dengan sebuah kemasan kecil.

4. Mengkonsumsi Daya yang Rendah Perangkat mobile menghabiskan sedikit daya dibandingkan dengan mesin desktop. Perangkat ini harus menghemat daya karena mereka berjalan pada keadaan dimana daya yang disediakan dibatasi oleh baterai-baterai.

5. Kuat dan Dapat Diandalkan

Karena perangkat mobile selalu dibawa kemana saja, mereka harus cukup kuat untuk menghadapi benturan-benturan, gerakan, dan sesekali tetesan-tetesan air.

6. Konektivitas yang Terbatas

Perangkat mobile memiliki bandwith rendah, beberapa dari mereka bahkan tidak tersambung.
Kebanyakan dari mereka menggunakan koneksi wireless.

7. Masa Hidup yang Pendek

Perangkat-perangkat konsumen ini menyala dalam hitungan detik kebanyakan dari mereka selalu menyala. Coba ambil kasus sebuah handphone, mereka booting dalam hitungan detik dan kebanyakan orang tidak mematikan handphone mereka bahkan ketika malam hari. PDA akan menyala jika anda menekan tombol power mereka.

\section{JQuery Mobile}

JQuery Mobile adalah sebuah framework berbasis JavaScript. JQuery sama dengan JavaScript Library yaitu kumpulan kode atau fungsi JavaScript siap pakai sehingga mempermudah dan mempercepat kita dalam membuat kode JavaScript.

Hal yang menarik dari JQuery penekanan interaksi antara JavaScript dan HTML. JQuery pertama kali dirilis pada tahun 2006 oleh John Resig. JQuery memiliki slogan "Write less, do more" yang artinya kesedarhanaan dalam penulisan kode, tapi dengan hasil yang lebih banyak. Selanjutnya JQuery akan berkembang lebih lanjut untuk perangkat mobile yang dinamakan JQuery Mobile.

Dengan kemudahan yang ada pada JQuery Mobile akan sangat membantu dalam membuat sendiri aplikasi untuk web mobile phone. Aplikasi ini akan membuat mobile phone anda menjadi lebih asyik digunakan. Adapun kemampuan yang dimiliki Library JQuery antara lain:

1. Mampu mengakses bagian halaman tertentu dengan mudah.

2. Mampu mengubah tampilan bagian halaman tertentu.

3. Mampu mengubah dari Halaman. 
4. Mampu merespon interaksi user dalam halaman.

5. Mampu menambahkan animasi ke halaman.

6. Mampu mengambil informasi dari server tanpa me-refresh seluruh halaman.

7. Mampu menyederhanakan kode JavaScript lainnya. (Wahana Komputer, 2012:02)

\section{PHP}

PHP merupakan singkatan dari Hypertext Preprocessor yaitu bahasa pemrograman web server-side yang bersifat open source. PHP merupakan script yang terintegrasi dengan HTML dan berada pada server (server side HTML embedded scripting). PHP adalah script yang digunakan untuk membuat halaman website yang dinamis. Dinamis berarti halaman yang akan ditampilkan dibuat saat halaman itu diminta oleh client. Mekanisme ini menyebabkan informasi yang diterima client selalu yang terbaru/up to date. Semua script PHP dieksekusi pada server di mana script tersebut dijalankan.

PHP memiliki beberapa kelebihan yang tidak dimiliki oleh bahasa-bahasa sejenisnya, yaitu:

1. Bahasa pemrograman PHP adalah sebuah bahasa script yang tidak melakukan sebuah kompilasi dalam penggunaanya.

2. Web Server yang mendukung PHP dapat ditemukan dimana - mana dari mulai IIS sampai dengan apache, dengan configurasi yang relatif mudah.

3. Dalam sisi pengembangan lebih mudah, karena banyaknya milis milis dan developer yang siap membantu dalam pengembangan.

4. Dalam sisi pemahamanan, PHP adalah bahasa scripting yang paling mudah karena referensi yang banyak.

5. PHP adalah bahasa open source yang dapat digunakan di berbagai mesin (linux, unix, windows) dan dapat dijalankan secara runtime melalui console serta juga dapat menjalankan perintah-perintah sistem. (Anhar, 2010:3)

\section{CSS}

CSS (Cascading Style Sheet) adalah suatu teknologi yang di gunakan untuk memperindah tampilan halaman web (situs). Singkatnya dengan menggunakan CSS, kita dapat menentukan tampilan suatu elemen yang sama pada setiap halaman sehingga kita tidak perlu melakukan penulisan kode program secara berulang-ulang untuk menampilkan tampilan yang sama. Di dalam pemrograman game, biasanya CSS digunakan untuk membangun tampilan antarmuka pengguna (user interface) yang bertema sama. (Adhi Prasetio, 2014:252)

\section{JavaScript}

JavaScript merupakan bahasa pemrograman berbasis client, artinya bahasa ini berjalan pada sisi browser pengguna, bukan pada server. Salah satu keuntungan dari bahasa ini adalah ringan karena berjalan pada masing-masing browser dan pekerjaan tidak dibebankan pada server. Jika diakses oleh 1000 orang maka setiap beban akan ditanggung oleh masing-masing browser, bukan server yang menanggung eksekusi 1000 pengakses tersebut. (Nugroho, 2012 :

\section{MySQL}


MySQL adalah sebuah program database server yang mampu menerima dan mengirimkan datanya dengan sangat cepat, multi user serta menggunakan standar SQL (Structured Query Language)". Dengan menggunakan MySQL server maka data dapat diakses oleh banyak pemakai secara bersamaan sekaligus dapat membatasi akses para pemakai berdasarkan previllage (hak user) yang diberikan. MySQL menggunakan bahasa SQL (Structure Query Language) yaitu bahasa standar pemrograman database. Adapun keunggulan dari MySQL adalah sebagai berikut:

1. Bersifat open source, artinya program ini bersifat free atau bebas digunakan oleh siapa saja tanpa harus membeli dan membayar lisensi kepada pembuatnya.

2. MySQL merupakan sebuah database server, jadi dengan menggunakan database ini dapat menghubungkannya ke media internet sehingga dapat diakses dari jauh.

3. MySQL merupakan sebuah database yang mampu menyimpan data berkapasitas sangat besar hingga berukuran Gigabyte sekalipun.

4. Sistem softwarenya tidak memberatkan kerja dari server atau komputer, karena dapat bekerja di background.

5. MySQL didukung oleh driver ODBC, artinya database MySQL dapat diakses menggunakan aplikasi apa saja termasuk berupa visual seperti Delphi maupunVisual Basic.

6. Cukup aman karena memiliki password untuk mengaksesnya Mendukung field yang dijadikan sebagai kunci primer dan kunci unik. (Adhi Prasetyo, 2014 : 183)

\section{METODE}

\section{Identifikasi Masalah}

Identifikasi masalah adalah suatu tahapan yang penting dalam suatu penelitian. Permasalahan yang terpenting dalam penelitian ini yaitu kurang perananan orang tua dalam pengawasan anak-anaknya di sekolah.

\section{Analisa Masalah}

Analisis adalah penguraian dari suatu pembahasan, dalam hal ini pembahasan mengenai perancangan sistem monitoring siswa berbasis Android yang berguna untuk melakukan pengawasan terhadap proses belajar anak di sekolah.

\section{Perancangan dan Pembuatan Sistem}

Pada tahap ini dilakukakan perancangan logika program dengan menggunakan beberapa tool seperti ERD, DFD dan Flowchart. Proses perancangan dimulai dari perancangan desain antar muka inputan atau perancangan fisik, perancangan algoritma program dan perancangan output.

\section{Pengujian dan Implementasi}

Pengujian perlu dilakukan terhadap sistem yang baru untuk menghindari terjadinya kesalahan. Setelah sistem selesai diuji tanpa kesalahan maka sistem monitoring siswa ini dapat diimplementasikan di SMAN 1 Bandar Sekijang.

Implementasi adalah suatu tindakan atau pelaksanaan dari sebuah rencana yang sudah disusun secara matang dan terperinci. Tahap implementasi adalah prosedur yang harus dilakukan untuk menyelesaikan desain sistem yang ada dalam dokumen rancangan sistem yang telah disetujui, serta menguji, menginstal dan mulai menggunakan sistem baru. Secara umum tujuan dari tahapan implementasi ini adalah untuk melaksanakan 
uji coba atas konsep pengembangan sistem yang telah disusun.

Metode yang digunakan dalam pembuatan dan penyelesaian sistem monitoring siswa berbasis mobile ini menggunakan metode waterfall

Menurut Olson (2001), model Waterfall adalah suatu metode yang memberikan umpan balik antara setiap tahapan proyek untuk meminimalisasikan pengulangan pekerjaan. Model waterfall dalam SDLC terdiri dari tahapan-tahapan yang meliputi :

1. System feasibility adalah studi kelayakan dengan menetukan konsep yang diperlukan bagi produk software serta siklus proyek.

2. Software plans and requirement adalah spesifikasi fungsi, tampilan dan kinerja yang dibutuhkan produk software secara rinci.

3. Product design adalah spesifikasi dari seluruh rancangan hardware dan software, struktur pengendalian, struktur data bagi produk dan komponen lainnya yang diperlukan sebagaikan dokumen bagi user dan tahap testing.

4. Detailed design adalah spesifikasi seluruh rancangan struktur pengendalian, struktur data, hubungan tampilan ukuran, kunci algoritma dan asumsi bagi setiap komponen program.

5. Code adalah komponen program secara keseluruhan.

6. Integration adalah penyatuan masing-masing fungsi komponen agar software dapat bekerja seharusnya. Operation and maintenance adalah perawatan sistem yang telah dibuat.

\section{HASIL}

\section{Hasil Sistem yang Dibuat}

Hasil dari pembuatan Sistem Monitoring Siswa Berbasis Android di Sekolah SMAN 1 Bandar Sekijang Kabupaten Pelalawan adalah sebagai berikut:

\section{Perancangan Input}

Perancangan input merupakan perancangan yang berguna untuk memasukkan data-data yang dibutuhkan ke dalam sistem informasi.

\section{Tampilan Login}

Berikut ini adalah tampilan login. Menu login ini berfungsi agar user dapat mengakses sistem dan mengelola data-data yang ada di database sesuai hak akses masingmasing. Tampilan ini merupakan langkah pertama untuk masuk ke menu utama. Untuk masuk ke menu utama, user harus memasukkan user dan password dengan benar. Gambar 1 merupakan tampilan login Sistem Monitoring Siswa Berbasis Android di Sekolah SMAN 1 Bandar Sekijang Kabupaten Pelalawan .

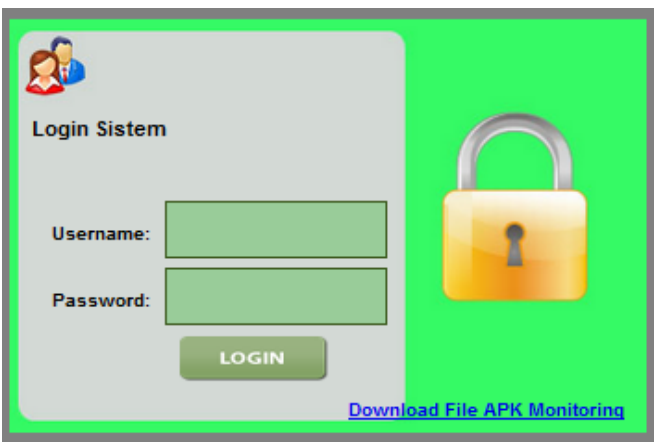

Gambar 1. Form Login

\section{Tampilan Menu Utama}

Menu utama ini tanda bahwa user telah login dan dapat mengakses sistem untuk melakukan pengolahan data sesuai dengan hak akses yang dimilikinya. 
Gambar 2 menunjukkan tampilan menu utama.

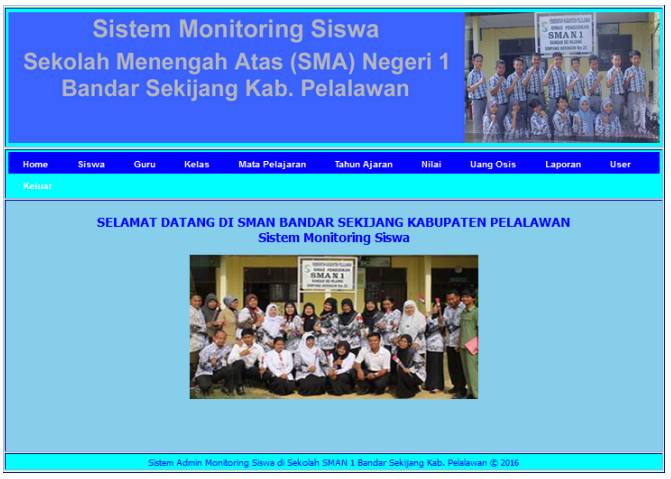

Gambar 2. Form Menu Utama

Pada menu utama admin dapat memilih beberapa pilihan untuk menginput data seperti data guru, data siswa, data kelas, data matapelajaran, data kehadiran dan datauang osis. Pada munu guru dapat melihat nilai dan menginput nilai.

\section{Tampilan Data Siswa}

Gambar 3 merupakan tampilan untuk data siswa SMAN SMAN 1 Bandar Sekijang.

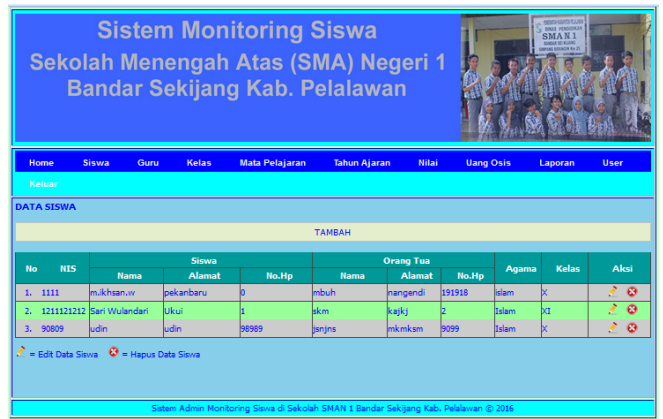

Gambar 3 Form Data Siswa

Dari menu data siswa ini dapat melakukan penginputan penambahan data siswa, menghapus data dan mengedit data. Disamping itu juga dapat melihat data-data siswa yang telah dinputkan.

\section{Form Tambah Data Siswa}

Gambar 4 adalah form untuk menambahkan data siswa SMAN SMAN 1 Bandar Sekijang.

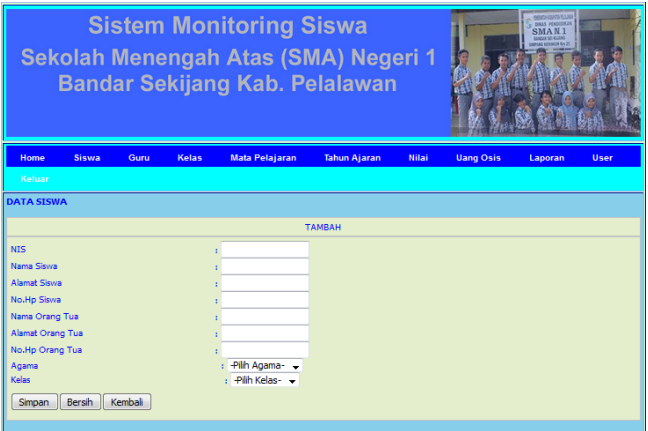

Gambar 4. Form Tambah Data Siswa

Pada form penambahan data siswa berisikan data-data mengenai siswa. Datadata yang diinputkan biasanya digunakan untuk laporan data siswa misalnya untuk rapor.

\section{Tampilan Data Guru}

Tampilan data guru SMAN SMAN 1 Bandar Sekijang dapa dilihat pada Gambar 5 berikut.

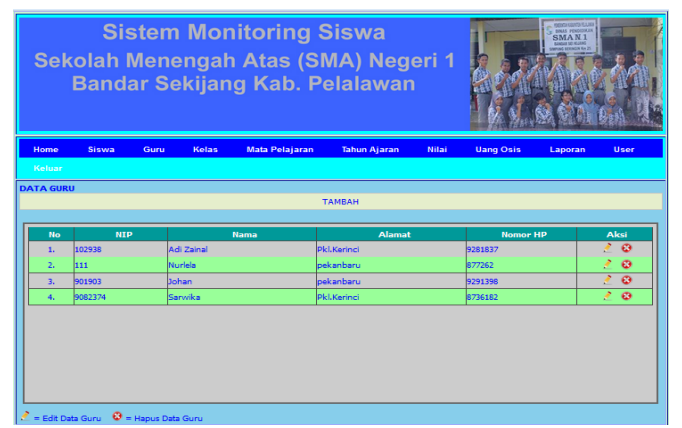

Gambar 5. Form Data Guru

Pada form penambahan data guru digunakan untuk menginput data-data guru disekolah terutama data-data dasar dari guru seperti nama guru, NIP guru, alamat dari guru dan Nomor HP guru yang dapat dihubungi.

\section{Form Tambah Data Guru}

Data guru dapat ditambah dengan mengisiform pada Gambar 6 . 


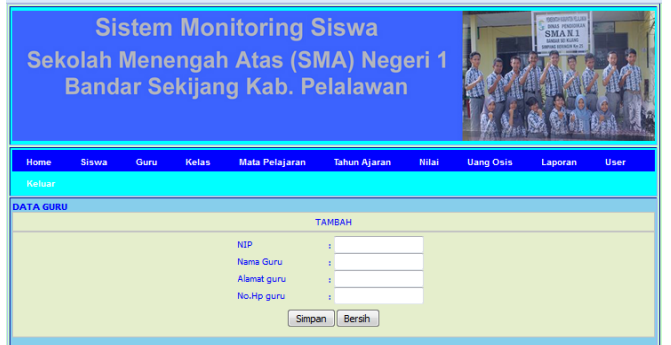

Gambar 6. Form Tambah Data Guru

\section{Tampilan Data Kelas}

Gambar 7 merupakan tampilan data kelas.

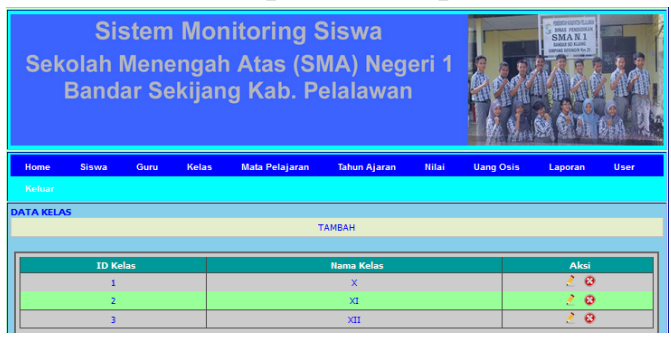

Gambar 7. Form Data Kelas

Pada penambahan data kelas ini digunakan untuk menambah kelas yang ada di sekolah.

\section{Form Tambah Data Kelas}

Gambar 8 merupakan form untuk tambah data kelas.

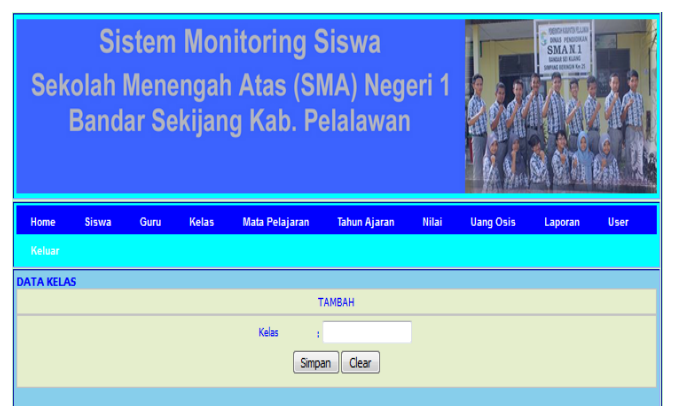

Gambar 8. Form Tambah Data Kelas

\section{Tampilan Data Mata Pelajaran}

Gambar 10 merupakan tampilan data mata pelajaran.

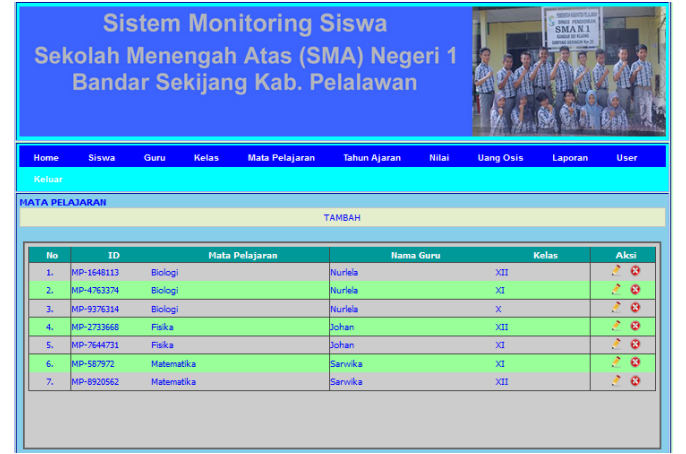

Gambar 10. Form Data Mata Pelajaran

Pada form data matapelajaran yang dapat dilakukan adalah menambah matapelajaran. Melihat semua matapelajaran yang ada. Data matapelajaran yang ingin diedit dan dihapus juga dapat dilakukan dari form ini.

\section{Form Tambah Mata Pelajaran}

Untuk tampilan input data mata pelajaran dapat dilihat pada Gambar 11 berikut ini.

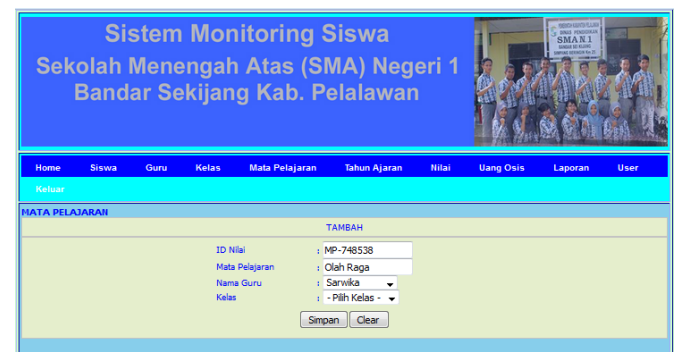

Gambar 11. Form Tambah Mata Pelajaran

Dari form penambahan matapelajaran yang diinput adalah idnilai, nama matapelajaran, nama guru pengampuh matapelajaran, dan nama kelas.

\section{Tampilan Data Nilai}

Tampilan data nilai siswa dapat dilihat pada gambar 12 berikut ini. 


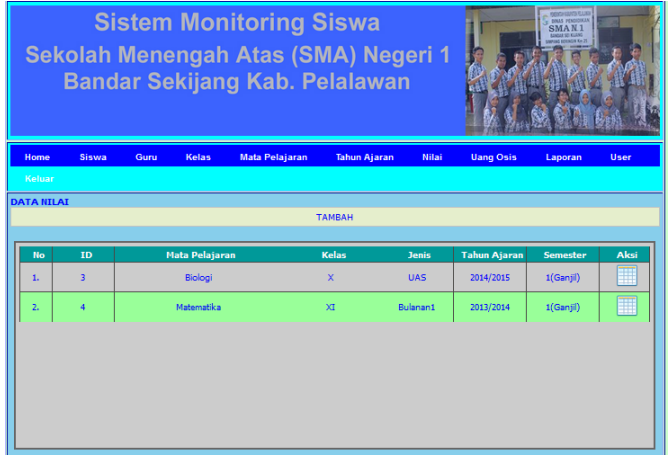

Gambar 12. Form Data Nilai

Pada form tersebut hannya dugunakan untuk melihat kategori nilai, nama matapelajaran, kelas, jenis nilai, tahun ajaran dan semester matapelajaran tersbut.

\section{Form Tambah Data Nilai}

Gambar 13 merupakan form untuk menambah data nilai siswa.

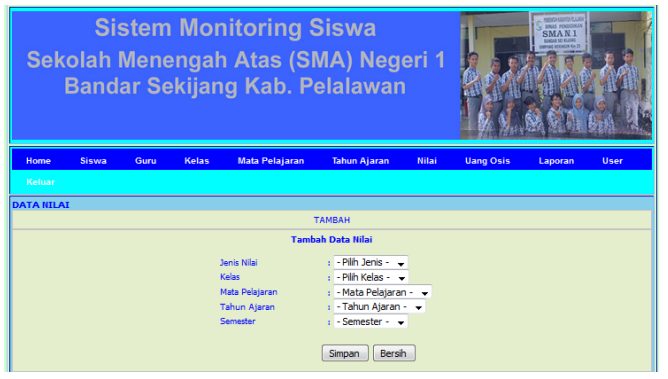

Gambar 13. Form Tambah Data Nilai

Sebelum nilai dapat di inputkan terlebih dahulu harus ditambahkan data mengenai matapelajarannya misalnya jenis nilai, kelas, nama matapelajaran, tahun ajaran dan semesternya. Apabila sudah terisi dengan lengkap mengenai matapelajaran tersebut maka data sudah dapat diisi.

\section{Tampilan Detail Nilai}

Tampilan detail nilai merupakan penjabaran data nilai siswa, dalam detail nilai, user dapat mengisikan nilai pada kolom nilai. Tampilan detail nilai dapat dilihat pada Gambar 14.

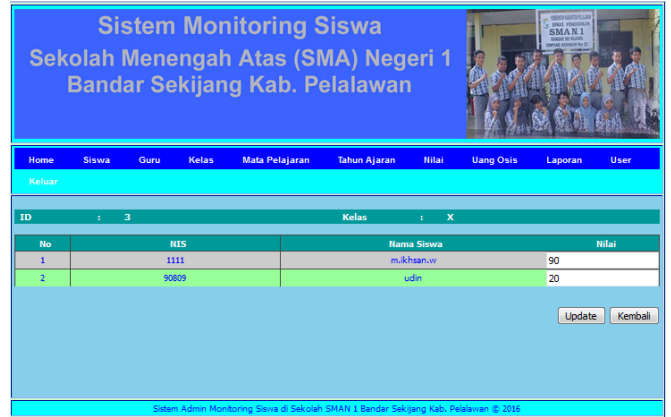

Gambar 14. Form Detail Nilai

\section{Tampilan Data User}

Gambar 15 merupakan tampilan data user.

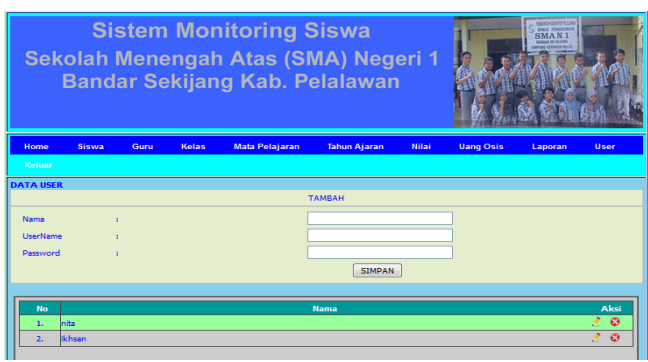

Gambar 15. Form Data User

Pada form data user digunakan untuk membuat user dan password untuk dapat mengakses aplikasi ini. Pembuatan user ini hanya untuk pembuatan user untuk mengakses aplikasi yang berbasis desktop.

\section{Form Pembayaran Uang Osis}

Gambar 16 merupakan tambah data pembayaran Osis.

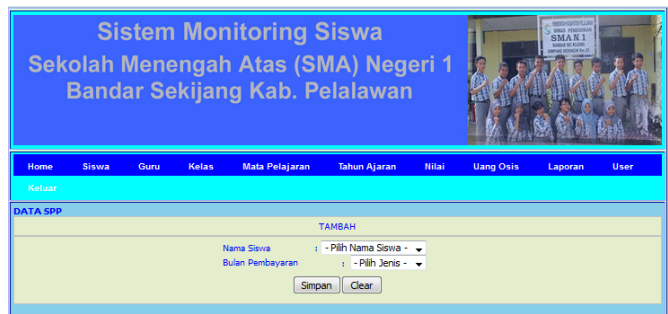

Gambar 16. Form Tambah Data Pembayaran Osis

Data pembayaran osis dapat dilakukan melalui menu ini. Untuk pembayaran uang osis dilakukan setiap bulan. 


\section{Menu Login android}

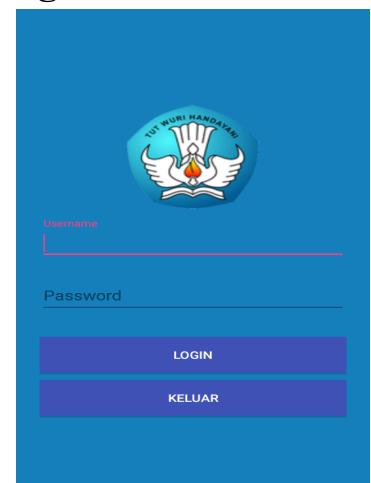

Gambar 17. Menu Login Aplikasi Android

Untuk dapat melihat monitoring nilai, absensi dan pembayaran osis yang dilakukan oleh orang wali murid tanpa mendatangi sekolah adalah dengan cara menginstalkan aplikasi android monitoring. Pada tampilan menu login tersebut dapat dilhat bahwa untuk dapat mengakses data terlebih dahulu harus mengisi username dan password yang sesuai. Terdapat dua tombol yaitu tombol login dan keluar. Tombol login berfungsi apabila username dan password telh diisi maka untuk mengeksekusinya dengan memilih tombol login. Sementara untuk tombol keluar berfungsi untuk keluar dari aplikasi.

\section{Menu Pilihan Monitoring}

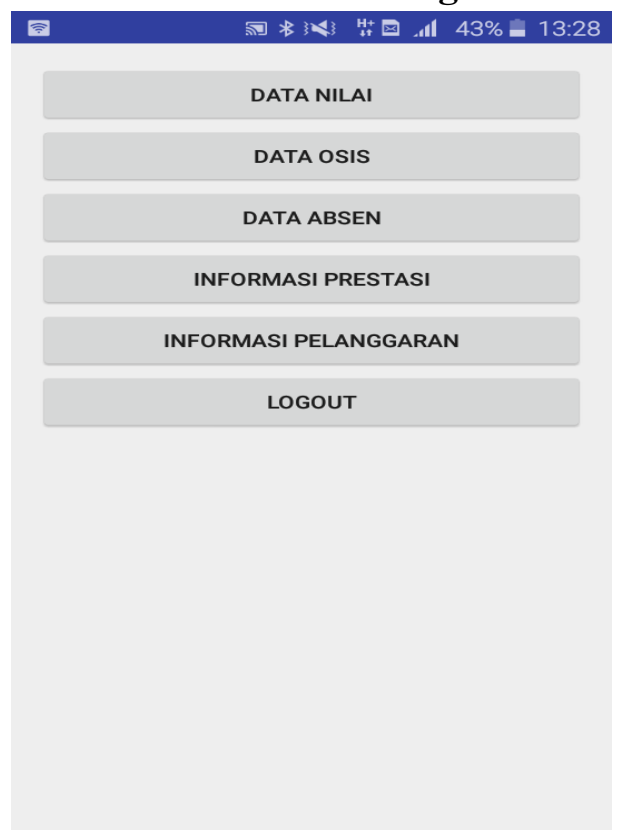

Gambar 18. Menu Monitoring pada Aplikasi Android

Pada gambar 4.26 terdapat empat pilihan yaitu data nilai, data osis, data absen dan logout. Pilihan data nilai berfungsi untuk melihat data nilai siswa bersangkutan, pilihan data osis berfungsi untuk melihat data pembayaran osis yang telah dilakukan, menu pilihan data absensi untuk melihat data kehadiran siswa bersangkutan. Sementara pilihan logout digunakan untuk keluar dari aplikasi.

\section{KESIMPULAN}

Setelah melakukan penelitian pada SMA 1 Bandar Sekijang Kabupaten Pelalawan, dari kelemahan-kelemahan sistem informasi pengolahan data yang ada maka didapatkan kesimpulan sebagai berikut:

1. Aplikasi monitoring dapat dijalankan dengan menggunakan teknologi berbasis mobile, sehingga pengguna mendapatkan manfaat lebih sesuai kebutuhan.

2. Aplikasi sistem monitoring dapat membantu orang tua dalam melakukan pengawasan terhadap perkembangan proses belajar anak-anaknya di sekolah.

3. Aplikasi sistem monitoring dapat membantu guru-guru atau pihak sekolah dalam proses pencatatan perkembangan belajar murid-muridnya di sekolah.

\section{DAFTAR PUSTAKA}

[1]. Anhar, 2010, Panduan Menguasai PHP \& MYSQL Secara Otodidak, Media Kita, Jakarta

[2]. Buyens, Jim., 2001, Web Database Development, PT. Elex Media Komputindo, Jakarta 
[3]. Cahyadi, Arief Faddilah. 2011, [7]. Nugroho, Andi Taru., 2012, "Perancangan Sistem Informasi Monitoring Akademik Siswa Smp N 72 Jakarta Pusat Berbasis Web". jakarta

[4]. Fikri, Azkal., 2012, Aplikasi Short Message Service (SMS) Gateway Untuk Layanan Informasi Registrasi Administrasi Mahasiswa, Jurnal, Universitas Pendidikan Indonesia

[5]. Jogiyanto, H.M., 2004, Analisa \& Desain Sistem Informasi, Andi Offset, Yogyakarta

[6]. Jogiyanto, H.M., 2009, Sistem Teknologi Informasi. Yogyakarta, Andi Offset, Yogyakarta

[7]. Nugroho, Andi Taru., 2012,
Pemrograman Game Berbasis Web Menggunakan JavaScript dan HTML5, Andi Offset, Yogyakarta

[8]. Purnama, Rangsang., 2010, Mari Mengenal J2ME Java 2 Micro Edition, Prestasi Pustaka, Jakarta

[9]. Prasetio, Adhi., 2014, Buku Sakti Webmaster, Media Kita, Jakarta

[10]. Roger S. Pressman, 2005, Rekayasa Perangkat Lunak Pendekatan Praktis: Yokyakarta: ANDI

[11]. Wahana Komputer. 2013, Step By Step Menjadi Programmer Android, Andi Offset, Yogyakarta 